\title{
Price reversal as potential expiration day effect of stock and index futures: evidence from Warsaw Stock Exchange
}

\section{Introduction}

Since 1986, when Stoll and Whaley published their first article about expiration day effects of index options and futures on the US market, many authors have researched the anomalies observable on different equity markets on days of derivatives' expirations. Such undesirable effects can be especially strong on days when several derivatives expire. Stoll and Whaley (1990) researched the effects of the so-called "triple witching days" when index futures, index options, and options on index futures expired simultaneously. In the literature, potential anomalies of expiration days on the main market are divided into price effects and volume effects. Alkebäck and Hagelin (2004) described the possible sources of these effects. The first one is the activity of arbitragers who unwind their positions on the stock market. If, during a contracts' life, the difference between the contract price and its theoretical value (basis) is non-zero, arbitrage transactions can be conducted only if the difference is great enough to exceed the required transaction costs. Arbitragers open opposite positions on the equity market and the derivative market. Unwinding positions on the equity market is always connected with buying or selling shares, while on the derivative market, only unwinding before the expiration demands trading. Thereupon, as Stoll and Whaley wrote (1987), it is useful for arbitragers to keep their positions until a derivative's expiration, as (in this case) the liquidation does not require any activity on the derivative market and thereby does not involve unnecessary transaction costs. If there are many arbitragers unwinding their positions in the same direction, price effects are possible.

\footnotetext{
* AGH University of Science and Technology, Faculty of Management, Department of Application of Mathematics in Economics, e-mail: msuliga@zarz.agh.edu.pl
} 
The second source of expiration effects specified by Alkebäck and Hagelin (2004) arises from the activity of speculators. Investors who have naked positions in expiring contracts can try to manipulate its settlement price by the appropriate transactions on the equity market. Affecting the underlying asset price, they simultaneously affect the settlement price of the contract.

Such increased activity of investors on an expiration day should be reflected in increased price volatility. Furthermore, if the price effect is drawn mostly by arbitragers unwinding in the same direction, abnormal price changes can be observed. Intensified activity of speculators can also abnormally lower or raise the underlying assets' price upon expiration. After the expiration, however, prices should return to a "normal" level. Stoll and Whaley (1986) wrote about price reversal after expiration as a second potential price effect. Beyond these, trading volume that was significantly higher than on non-expiration days has been reported by many researchers as an effect of expiration day. On the markets where the settlement price is determined on the basis of stock prices from a certain time interval (usually from the last trading hour or the last 30 minutes of trading), the trading volume is especially high during this time span.

Most researchers study the expiration day effects of index futures and index options. Derivatives on individual stocks are less common; for this reason, they rarely form a subject of research. Results of the studies of expiration day effects vary depending on the research method, market under study, and period of time from which the data originates. Stoll and Whaley (1986) proposed a comparison of returns and trading volume of an underlying asset on expiration days to the corresponding returns and volume on control days by using some statistical tests. Significant differences between these variables on expiration and non-expiration days are evidence of the influence that the derivatives' expiration has on the equity market. Most other researchers have based their findings on this method, employing it in sundry variations to daily or intraday data.

The existence of a volume effect of an index futures and index options expiration days was first confirmed for the US market (Stoll and Whaley [1986, 1987]; Chen and Williams [1994]). Since then, research on expiration effects has been extended to other markets. As a result, the increased trading volume of underlying assets on the day of a derivative's expiration was detected on the markets of Japan (Karolyi [1996]), Germany (Schlag [1996]), Australia (Stoll and Whaley [1997]), Sweden (Alkebäck and Hagelin [2004]), Poland (Morawska [2007]), China (Fung and Jung [2009]), Spain (Illueca and Lafuente [2006]), and India (Narang and Vij [2013]), among others.

While the existence of the volume effect of an expiration day seems to be widespread, researchers are not unanimous about the price effects. Increased volatility around the expiration has been reported, for example, by Stoll and 
Whaley (1987, 1997), Day and Lewis (1988), Chamberlain et al. (1989), Diz and Finucane (1998), Alkebäck and Hagelin (2004) (for the earlier of two sub-periods under study), Chow et al. (2003), Lien and Li (2005), Illueca and Lafuente (2006), Morawska (2007), and Narang and Vij (2013). Other authors did not find evidence of a volatility effect (see Chen and Williams [1994], Karolyi [1996], Bollen and Whaley [1999]). This ambiguity in the results surely indicates differences between the markets on that score, but this can also come from that facts that researchers use various volatility measurements for data on different frequencies and that they study the expiration of different derivatives.

The occurrence of the phenomenon of price reversal after expiration was identified, for example, by Stoll and Whaley (1987) and Chamberlain et al. (1989). Definitely more researches report no price reversal effect (see, e.g., Karolyi [1996], Stoll and Whaley [1997], Alkebäck and Hagelin [2004], Chow et al. [2003], Morawska [2007], Fung and Jung [2009], and Narang and Vij [2013]). Schlag (1996) found reversal only in case of futures that expire at the open. For options expiring at the close, no price reversal was found. Stoll and Whaley $(1986,1987)$ defined a few ways of calculating the reversal based on the comparison between signs of an underlying asset return on the expiration day and the return on the next day. These definitions were then used by others (e.g., Bollen and Whaley [1999], Chamberlain et al. [1989], Alkebäck and Hagelin [2004], Chow et al. [2003], and Morawska [2007]) to variously defined returns.

The above-mentioned authors studied either futures or options (or both) expiring simultaneously. This research only studies futures, as options are still not very popular derivatives on the Polish terminal market. According to the author's knowledge, the only research about futures' expiration day effects on the Polish equity market was conducted by Morawska (2004, 2007). Unfortunately, the full text of the first article (2004) is not available to the author. In (2007), Morawska studies 15 futures on WIG20 expirations between the first of January 2002 and $30^{\text {th }}$ of June 2006. These contracts expired each year on the third Friday of March, June, September, and December. Each expiration date was researched separately. Following Stoll and Whaley (1986), the WIG20 Index returns and volume is studied by comparing the expiration days with control days. Control days are defined as the first and second Friday of the expiration month.

As a measurement of abnormal trading volume, Morawska (2007) took the relative trading volume at the close - the ratio of the volume values of particular stocks in the index from the last hour of the trading day to their volume values from the whole day. On 7 out of 15 events, she found a significantly higher average relative trading volume on expiration days than on control days. The volatility effect is measured by the variance of one-minute intraday WIG20 returns. To check if an index price reversal after expiration can be observed, 
Morawska (2007) compares the sign of the index return from the last $30 \mathrm{~min}$ utes on the expiration day with the sign of the return after the close (defined as a return calculated from the opening rate on the day after expiration and the rate of the index at the close of expiration day). The volatility effect and price reversal are also measured by a comparison with the control group. In 14 out of 15 events, abnormal volatility was detected. Price reversal, on the other hand, occurred only once.

The first futures contract on the WIG20 Index was introduced in 1998. This was also the first derivative on the Polish market (which has remained the mostliquid one to this day). Since 1998, more and more futures have been introduced; however, some of them have already been withdrawn from the market. Currently, two types of index futures are being traded: futures on the WIG20 Index and futures on the mWIG40 Index. Since 2001, futures on individual stocks have also been introduced to the Polish derivative market. Since the research conducted by Morawska (2007) covers only a period of six years (when the derivative market was relatively young) and only studies futures on the WIG20 Index, it seems to be desirable to extend the research of expiration day effects on the Polish equity market by taking into account more types of derivatives and expanding the time span of a study.

In this paper, we focus only on the price reversal effect of futures' expirations and check, if the effect is observable on the Warsaw Stock Exchange. Studies from other markets are not unequivocal about this effect, so an in-depth analysis of this phenomenon is desirable. Concededly, Morawska (2007) wrote that this effect does not exist on the Warsaw Stock Exchange, but this study broadens her research in several ways. First of all, beyond futures on the WIG20 Index, futures on the mWIG40 Index and futures on individual stocks are also studied. What is more, the derivative market today is more developed and liquid, so there are probably better conditions for speculations and arbitrage that can result in expiration day effects. The research covers a much-longer time span that was considered by Morawska (2007). The occurrence of a potential price reversal effect is also tested in different ways. First, an appropriate regression model is used to determine an underlying asset's returns. Second, the measures of reversal proposed by Stoll and Whaley $(1986,1987)$ are calculated. Finally, abnormal price changes around expiration are tested with the use of event study methodology, which has not been employed to the analysis of expiration day effects so far (according to this author's knowledge).

The structure of the paper is as follows: Section 2 describes the data and methodology; empirical results of the research are demonstrated and discussed in Section 3; and Section 4 concludes the paper. A list of futures along with their underlying assets used in this study is presented in the appendix. 


\section{Data and methodology}

The dataset contains the daily markings of futures on individual stocks and futures on the indexes (WIG20 and mWIG40) as well as the markings on their underlying assets within a period from the first of January 2001 to the $31^{\text {st }}$ of December 2016. The choice of such a time span was dictated by the availability of data at www.gpwinfostrefa.pl. During this period, there were 64 expiration days of futures on the WIG20 Index. Futures on the individual stocks were researched over a somewhat shorter time span (starting from 2003). During the early years of the markings, the frequency of the expiration of some futures on stocks changed (for example, in 2001 and 2002, futures on the PKN expired every month); therefore, the time horizon of the research is chosen so as to contain only futures with the same characteristics in the sample. The first futures contract on the mWIG4o Index expired in May 2007, so there are 39 days of this contract's expiration in the dataset.

Except for index futures and stock futures, European put and call options on the WIG20 Index (which expire on the third Friday of each month) are also available on the Polish derivative market. However, options have only started to become more popular over the last few years, and there is still much-lower interest in these instruments than in futures (in 2016, 95.4\% of the total volume value on the derivative market came from futures). For this reason, the author only takes futures into consideration, bearing in mind that their expiration occurs simultaneously with the expiration of WIG20 options.

All of the contracts that are the subject of this study have some common characteristics. The value of each contract is equal to its rate multiplied by a given number. Futures on the individual stocks have a multiplier of 100 or 1000 . Futures on the mWIG40 (as well as futures on the WIG20 through 2013) have a multiplier of 10. In September 2013, futures on the WIG20 with a multiplier of 20 were put on the market. The contracts expire simultaneously (four times a year - namely, on the third Friday of each March, June, September, and December) and are listed for nine months. The contracts are cash settled. Every day, the settlement price of the contract is defined as its closing price. The final settlement rates for index futures are calculated as the arithmetic mean of all index values of a continuous quotation during the last hour of trading on the expiration day and its value at the close (after eliminating the five highest and five lowest values). In the case of futures on the individual stocks, the final settlement price is equal to the rate of the underlying asset used in the last transaction made on the equity market on the expiration day. The list of futures used in the research (as well as the names of their underlying assets and their multipliers) are presented in Table 6 in the appendix. In the table, the first expiration means the first one included in the research. If some contract was introduced before the period under study, it is not its first expiration at all. 
In this article, the effect of price reversal after expiration is explored. The existence of this effect is researched in three different ways. The results from the analysis of expiration days are compared with the analogous results from control days. To obtain the control group (equinumerous to the research group), control days are defined as the third Friday of January, April, July, and October. First, a simple regression model is employed to the returns of the futures' underlying assets:

$$
\boldsymbol{R}_{i, 1}=\alpha+\beta \boldsymbol{R}_{i, 0}+\varepsilon_{i}
$$

where $R_{i, 0}$ represents the return on the expiration or control day, respectively, while $R_{i, 1}$ represents the return on the day following the expiration day or control day, respectively. Two regression models are checked. In both, independent variable $\boldsymbol{R}_{i, 0}$ is defined as the daily logarithmic rate of the return of an underlying asset, but the dependent variable changes. In the first model, this is represented by the logarithmic rate of return on the day following the event day, while in the second model, $R_{i, 1}$ is defined as the overnight return; that is, the natural logarithm of the ratio of return on the opening on the day after the expiration (or control) day to return at the close on the event day.

Second, the three measures of price reversal used by Alkebäck and Hagelin (2004) and taken from Stoll and Whaley (1987) and Chamberlain et al. (1989) are calculated for the expiration and control days.

Type 0 reversal:

$$
R E V_{i, 0}=\left\{\begin{array}{cll}
\boldsymbol{R}_{i, 1} & \text { if } & \boldsymbol{R}_{i, 0}<0 \\
-\boldsymbol{R}_{i, 1} & \text { if } & \boldsymbol{R}_{i, 0} \geq 0
\end{array}\right.
$$

has a positive value in the case of price reversal and a negative value in the case of continuation. The average $R E V_{i, 0}$ is calculated in the group of expiration days and control days, respectively, and the $t$-test is used to check if the difference between them is significant.

Type 1 reversal:

$$
R E V_{i, 1}=\left\{\begin{array}{cc}
\left|R_{i, 1}\right| & \text { if } \operatorname{sign}\left(R_{i, 1}\right) \neq \operatorname{sign}\left(R_{i, 0}\right) \\
0 & \text { otherwise }
\end{array}\right.
$$

and Type 2 reversal:

$$
R E V_{i, 2}=\left\{\begin{array}{cc}
\left|R_{i, 0}\right| & \text { if } \operatorname{sign}\left(R_{i, 1}\right) \neq \operatorname{sign}\left(R_{i, 0}\right) \\
0 & \text { otherwise }
\end{array}\right.
$$


have only nonnegative values. In contrast to the Type 0 reversal, these measures are only descriptive, as the above-mentioned authors do not give any tests that could determine whether the reversal is significant. The average $R E V_{i, 1}$ and $R E V_{i, 2}$ are calculated in the group of expiration days and control days, respectively. The greater the value of the average measure, the stronger the phenomenon of price reversal. As in the case of the regression models, these measures are defined in two ways (depending on the definition of $R_{i, 1}$ ).

Finally, the event study methodology is used to more-deeply explore the phenomenon of abnormal price changes around the expiration of the futures. This methodology is usually used to check the impact of different unexpected events on the equity market (see, for example, Gurgul [2006]). According to the author's knowledge, it has yet to be employed to the analysis of expiration day effects. Although future expiration cannot be perceived as an unexpected event in terms of the expiration date (which is preconceived), the impact of this event on the stock returns is unforeseeable (as it depends on the investors' activity on this day). In the author's opinion, event study analysis applied in an appropriate manner should be able to detect price reversal after expiration. However, as it is usually employed for abnormal returns, the reversal has a slightly different definition in this case than in the previously mentioned measures.

The analysis is used separately for expiration days and control days, and the results are compared. The event day (expiration day and control day, respectively) is designated by $t=0$. The pre-event window covers 45 days from $t=-50$ to $t=-6$. It is as wide as possible to avoid an overlap with the previous event window. The event window contains 11 days around the date of the event; it starts 5 days before the expiration day or control day, respectively $(t=-5)$, and ends 5 days after it $(t=5)$.

Abnormal returns for each day in the pre-event and event windows are defined as the difference between the actual rate of return and its expected value:

$$
A R_{i, t}=R_{i, t}-E\left(R_{i, t}\right)
$$

is the logarithmic rate of return of the shares or index on day $t$. For the individual stocks, the expected returns are calculated with the classical market model from the estimation window:

$$
\boldsymbol{R}_{i, t}=\alpha+\beta \boldsymbol{R}_{m, t}+\varepsilon_{i, t}
$$

where $R_{m, t}$ is the logarithmic rate of the WIG20 return and $\varepsilon_{i, t}$ is the error on a given day. For the WIG20 and mWIG40 indexes, the expected returns are equal to the mean of returns in the estimation window, as the market model cannot be applied 
in this case. The use of parametric tests in the event study requires the normal distribution of residuals, a lack of autocorrelation, and homoskedasticity. Most of the data fails to satisfy at least one of these assumptions. For this reason, the non-parametric generalized rank test proposed by Kolari and Pynnönen (2001) is applied. As the authors explain, the test is robust for event-induced volatility and to a certain degree of cross-correlation caused by event day clustering. Moreover, it is reasonably robust to the autocorrelation of abnormal returns. Finally, it does not require an assumption about the normality of abnormal returns, and its power dominates the power of popular tests used in the event studies.

To construct the test statistic, abnormal returns for each event are standardized; that is, they are divided by the standard deviation of abnormal returns from pre-event window:

$$
S A R_{i, t}=A R_{i, t} / S\left(A R_{i}\right)
$$

Thereafter, adjusted standardized abnormal returns are computed in order to account for any event-induced increase in volatility:

$$
S A R_{i, t}^{\prime}=\left\{\begin{array}{cc}
S A R_{i, t} & t=-50, \ldots,-6 \\
S A R_{i, t} / S\left(S A R_{t}\right) & t=-5, \ldots, 5
\end{array}\right.
$$

where $S\left(S A R_{t}\right)$ is a cross-sectional standard deviation of standardized abnormal returns defined as:

$$
S\left(S A R_{t}\right)=\sqrt{\frac{1}{N-1} \sum_{i=1}^{N}\left(S A R_{i, t}-\overline{S A R_{t}}\right)^{2}}
$$

and $N$ is the number of events in the sample. $S A R_{i, t}^{\prime}$ are random variables with an expected value of zero and a unit variance under the null hypothesis of no event effect. Abnormal returns on each day $t_{0}$ in the event window are tested separately. For this reason, the demeaned standardized abnormal ranks are defined as:

$$
U_{i, t}=\frac{\operatorname{rank}\left(S A R_{i, t}^{\prime}\right)}{T+1}-\frac{1}{2}
$$

for $i=1, \ldots, N$, and $t \in \Omega=\left\{-50, \ldots,-6, t_{0}\right\} . T-1$ is the length of the pre-event window, and $\operatorname{rank}\left(S A R_{i, t}^{\prime}\right)$ is the rank of $S A R_{i, t}^{\prime}$ within the group of adjusted standardized abnormal returns from the pre-event window and $S A R_{i, t_{0}}^{\prime}$. The null hypothesis about the no event effect is, thus, equivalent to the hypothesis that:

$$
E\left(U_{i, t_{0}}\right)=0
$$


This hypothesis is tested with the use of generalized rank test statistic $\tau_{\text {grank }}$ defined by Kolari and Pynnönen (2001) as:

$$
\tau_{\text {grank }}=Z \sqrt{\frac{T-2}{T-1-Z^{2}}}
$$

where:

$$
Z=\frac{\overline{U_{t_{0}}}}{S_{\bar{U}}}, \quad \overline{U_{t}}=\frac{1}{N} \sum_{i=1}^{N} U_{i, t}, S_{\bar{U}}=\sqrt{\frac{1}{T} \sum_{t \in \Omega} \bar{U}_{t}^{2}}
$$

Under the null hypothesis of the no event effect, the distribution of the $\tau_{\text {grank }}$ statistic converges to $t$-student distribution with $T-2$ degrees of freedom when sample size $N$ increases.

Normally, an event study analysis is based on abnormal returns, which are defined as the difference between actual returns and their expected values. For an individual stock, the expected value is usually received from an appropriate model that describes the relationship between the return of the stock and the market rate of the return (see Gurgul [2006], page 41). Thus, the event study is able to detect price changes that are inconsistent with expectations. For example, a positive abnormal return on an expiration is a sign that the price on this day was higher than expected. The study is conducted it two clusters of events: expiration (or control) days with positive abnormal returns and expiration (or control) days with negative abnormal returns. In each of the clusters, the attention is focused on the day after the expiration. If the test statistic on day $t=1$ is significantly different from zero and has an opposite sign to the sign of abnormal returns on the event day, this is a signal that an unexpected change in price has taken place and that the change went the opposite direction of the change from the day before. This is not tantamount to saying that the price has changed in the opposite direction than the day before, so this conception of price reversal is slightly different than the one proposed by Stoll and Whaley (1986) and employed by other research. For example, if there is a rapidly growing trend in prices and an abnormal return is positive on the day of expiration, this means that the price rose even more than was expected. If, on the next day, the abnormal return is negative, this does not necessarily mean that the price dropped, but it is a signal that the trend was disturbed in the opposite direction than the day before (the trend was constricted). When a price reversal is defined as the change of the return's sign, the above-mentioned situation appearing as an effect of expiration is not taken into account. Thus, it is desirable to check whether the effect of a future's expiration day is reflected in the abnormal returns.

To avoid making the article too weighty, the results of the event study analysis conducted on the control groups are only briefly described, but they are not presented in the tables. However, these can be provided by the author upon request. 


\section{Empirical results}

\subsection{Results from analysis of regression models}

As an initial study of the price reversal effect of expiration, two regression models are matched to the returns of the futures' underlying assets. In the models, an independent variable represents the daily logarithmic rate of return on the expiration day (or control day), while the dependent variables are defined in two different ways and describe the returns on the day following the expiration day (or control day). In the case of a price reversal, the coefficient corresponding to the explanatory variable should be negative. Results from the analysis are presented in Table 1. Panel A presents the results from the model with the dependent variable defined as the logarithmic rate of return on the day following the event day. In Panel B, results from the model with the dependent variable defined as the overnight return (that is, the logarithm of the ratio of the return on the opening on the day after expiration or the control day to return at the close on the event day) are presented. The expiration and the control group each have 64 observations for WIG20, 39 observations for mWIG40, and 591 observations for the individual stocks.

Table 1

Results from regression models employed to returns of futures' underlying assets

\begin{tabular}{|c|c|c|c|c|c|c|}
\hline \multicolumn{7}{|c|}{ PANEL A } \\
\hline \multirow{2}{*}{$\begin{array}{c}\text { Underlying } \\
\text { asset }\end{array}$} & \multicolumn{3}{|c|}{ Expiration days } & \multicolumn{3}{|c|}{ Control days } \\
\hline & coefficient & estimate & p-value & coefficient & estimate & p-value \\
\hline \multirow[t]{3}{*}{ WIG20 } & $\alpha$ (intercept) & 0.000 & 0.986 & $\alpha$ (intercept) & -0.002 & 0.377 \\
\hline & $\beta\left(R_{i, 0}\right)$ & -0.128 & 0.376 & $\beta\left(R_{i, 0}\right)$ & 0.048 & 0.744 \\
\hline & \multicolumn{3}{|c|}{ Multiple $R^{2}: 0.013$} & \multicolumn{3}{|c|}{ Multiple $R^{2}: 0.002$} \\
\hline \multicolumn{7}{|c|}{ PANEL A } \\
\hline \multirow{2}{*}{$\begin{array}{c}\text { Underlying } \\
\text { asset }\end{array}$} & \multicolumn{3}{|c|}{ Expiration days } & \multicolumn{3}{|c|}{ Control days } \\
\hline & coefficient & estimate & p-value & coefficient & estimate & p-value \\
\hline \multirow[t]{3}{*}{ mWIG40 } & $\alpha$ (intercept) & 0.000 & 0.854 & $\alpha$ (intercept) & -0.002 & 0.307 \\
\hline & $\beta\left(R_{i, 0}\right)$ & -0.136 & 0.400 & $\beta\left(R_{i, 0}\right)$ & 0.084 & 0.753 \\
\hline & \multicolumn{3}{|c|}{ Multiple $R^{2}: 0,019$} & \multicolumn{3}{|c|}{ Multiple $R^{2}: 0.003$} \\
\hline
\end{tabular}


Price reversal as potential expiration day effect of stock and index futures...

Table 1 cont.

\begin{tabular}{|c|c|c|c|c|c|c|}
\hline \multirow{3}{*}{$\begin{array}{l}\text { individual } \\
\text { stocks }\end{array}$} & $\alpha$ (intercept) & 0.002 & 0,023 & $\alpha$ (intercept) & 0.000 & 0.747 \\
\hline & $\beta\left(R_{i, 0}\right)$ & -0.049 & 0,213 & $\beta\left(R_{i, 0}\right)$ & 0.252 & 0.000 \\
\hline & \multicolumn{3}{|c|}{ Multiple $R^{2}: 0.003$} & \multicolumn{3}{|c|}{ Multiple $R^{2}: 0.040$} \\
\hline \multicolumn{7}{|c|}{ PANEL B } \\
\hline \multirow{2}{*}{$\begin{array}{c}\text { Underlying } \\
\text { asset }\end{array}$} & \multicolumn{3}{|c|}{ Expiration days } & \multicolumn{3}{|c|}{ Control days } \\
\hline & coefficient & estimate & p-value & coefficient & estimate & p-value \\
\hline \multirow[t]{3}{*}{ WIG20 } & $\alpha$ (intercept) & 0.002 & 0.061 & $\alpha$ (intercept) & -0.002 & 0.077 \\
\hline & $\beta\left(R_{i, 0}\right)$ & -0.094 & 0.181 & $\beta\left(R_{i, 0}\right)$ & -0.050 & 0.502 \\
\hline & \multicolumn{3}{|c|}{ Multiple $R^{2}: 0,029$} & \multicolumn{3}{|c|}{ Multiple $R^{2}: 0,007$} \\
\hline \multirow[t]{3}{*}{ mWIG40 } & $\alpha$ (intercept) & 0.001 & 0.050 & $\alpha$ (intercept) & 0.001 & 0.743 \\
\hline & $\beta\left(R_{i, 0}\right)$ & 0.034 & 0.550 & $\beta\left(R_{i, 0}\right)$ & 0.249 & 0.977 \\
\hline & Multiple $R^{2}$ : & 0.010 & & Multiple $R^{2}$ : & 0.083 & \\
\hline \multirow{3}{*}{$\begin{array}{l}\text { individual } \\
\text { stocks }\end{array}$} & $\alpha$ (intercept) & 0.001 & 0.037 & $\alpha$ (intercept) & -0.002 & 0.002 \\
\hline & $\beta\left(R_{i, 0}\right)$ & -0.535 & 0.007 & $\beta\left(R_{i, 0}\right)$ & 0.017 & 0.581 \\
\hline & \multicolumn{3}{|c|}{ Multiple $R^{2}: 0.012$} & \multicolumn{3}{|c|}{ Multiple $R^{2}$ : 0.001} \\
\hline
\end{tabular}

Source: own calculations

In each of the three models from Panel A (for WIG20, mWIG40, and the individual stocks), the coefficient corresponding to the explanatory variable is negative in the group of expiration days, suggesting that the higher the rate of return on the event day, the lower the rate on the following day, and (conversely) a negative rate of return on the expiration day has a positive impact on the rate of return on the next day. Unfortunately, the coefficients are not statistically significant from zero, so this impact is not strong enough to be a convincing sign of a price reversal. In the control group, coefficient $\beta$ is positive in each of the models, but it is only statistically significant (at a 1\% level) in the case of an individual stock's returns. This is a confirmation that, on days without a futures' expiration, returns of the stocks tend to follow the trend. This feature seems to be disturbed by the expiration. In the WIG20 and mWIG40 index returns, there are no significant differences on the days with and without an expiration. The daily rate of return, employed as a dependent variable in the first model, contains information about the change in price during the whole day following the expiration. Thereby, many different events on this day can have an impact on it, disturbing its possibility to reflect the price reversal. As the models in Panel A 
do not provide satisfying clear-cut results, a second model is employed to check if it is possible that the price reversal after expiration is immediate and can be reflected in the overnight rather than daily returns. Thus, in the second model, the dependent variable is defined as the logarithm of the ratio of the price on the opening of the day after the expiration (or control) day to the price at the close of the event day.

In all of the models constructed for the indexes, coefficient $\beta$ does not differ significantly from zero. For the mWIG40 returns, this coefficient is even positive (but insignificant) in the group of expiration days. However, the results obtained for the individual stocks are interesting. Coefficient $\beta$ is negative and significant on expiration days yet positive (but not significant) on control says. This suggests that the price reversal appears directly after a future's expiration, while the continuation of the trend on ordinary days is connected with investor activities during the day and is reflected in the daily rather than overnight returns.

A slightly different regression model (but one that also describes the relationship between the returns on the expiration day and on the following day) was employed by Alkebäck and Hagelin (2004). They study futures on the OMX index and do not find a statistically significant reversal of the index returns after expiration. Narang and Vij (2013) also use some regression model (but definitely more complicated) for the daily data to evaluate the price and volume effects of an index derivative's expiration, and their results also indicate that there is no price reversal.

This preliminary research of regression models suggests that the expiration day effect may not be reflected in the index returns but might be visible in the prices of these stocks that set an underlying asset of a contract. In this case, an abnormal change in price on the expiration day may be immediately rectified after expiration and be reflected in the overnight stock returns. Further research will be conducted to support this thesis.

\subsection{Results from analysis of reversal measures}

Three measures of price reversal used in foregoing studies of futures' expiration effects (see, e.g., Stoll and Whaley [1987], Chamberlain et al. [1989], Alkebäck and Hagelin [2004]) are constructed for the returns of the WIG20 and $\mathrm{mWIG} 40$ indexes as well as for the individual stocks on the expiration and control days. As in the case of the regression models, the measures are defined in two different ways depending on the definition of the returns after expiration. These results are presented in Table 2. The expiration and control groups each have 64 observations for WIG20, 39 observations for mWIG40, and 591 observations for the individual stocks. 
Price reversal as potential expiration day effect of stock and index futures...

Table 2

Average price reversal measures in percentages as well as percentages of number of days with reversals

\begin{tabular}{|c|c|c|c|c|}
\hline \multicolumn{5}{|c|}{ Panel A } \\
\hline Underlying asset & Type of reversal & $\begin{array}{c}\text { Expiration } \\
\text { days [\%] }\end{array}$ & $\begin{array}{c}\text { Control } \\
\text { days [\%] }\end{array}$ & $\begin{array}{c}\text { p-value of } \\
\text { t-test }\end{array}$ \\
\hline \multirow[t]{4}{*}{ WIG20 } & Type O reversal & 0.036 & 0.091 & 0.858 \\
\hline & Type 1 reversal & 0.582 & 0.673 & - \\
\hline & Type 2 reversal & 0.543 & 0.587 & - \\
\hline & Percentage of reversals & $48 \%$ & $56 \%$ & - \\
\hline \multirow[t]{4}{*}{ mWIG40 } & Type O reversal & 0.096 & -0.176 & 0.343 \\
\hline & Type 1 reversal & 0.431 & 0.467 & - \\
\hline & Type 2 reversal & 0.479 & 0.280 & - \\
\hline & Percentage of reversals & $64 \%$ & $38 \%$ & - \\
\hline \multirow[t]{4}{*}{ individual stocks } & Type O reversal & 0.164 & -0.195 & 0.009 \\
\hline & Type 1 reversal & 0.899 & 0.822 & - \\
\hline & Type 2 reversal & 0.864 & 0.626 & - \\
\hline & Percentage of reversals & $53 \%$ & $46 \%$ & - \\
\hline \multicolumn{5}{|c|}{ Panel B } \\
\hline Underlying asset & Type of reversal & $\begin{array}{c}\text { Expiration } \\
\text { days [\%] }\end{array}$ & $\begin{array}{l}\text { Control } \\
\text { days [\%] }\end{array}$ & $\begin{array}{c}\text { p-value of } \\
\text { t-test }\end{array}$ \\
\hline \multirow[t]{4}{*}{ WIG20 } & Type O reversal & 0.050 & -0.035 & 0.587 \\
\hline & Type 1 reversal & 0.027 & 0.289 & - \\
\hline & Type 2 reversal & 0.451 & 0.599 & - \\
\hline & Percentage of reversals & $50 \%$ & $42 \%$ & - \\
\hline \multirow[t]{4}{*}{ mWIG40 } & Type O reversal & 0.022 & -0.077 & 0.474 \\
\hline & Type 1 reversal & 0.164 & 0.233 & - \\
\hline & Type 2 reversal & 0.322 & 0.310 & - \\
\hline & Percentage of reversals & $59 \%$ & $44 \%$ & - \\
\hline \multirow[t]{4}{*}{ individual stocks } & Type O reversal & 0.065 & -0.069 & 0,078 \\
\hline & Type 1 reversal & 0.417 & 0.407 & - \\
\hline & Type 2 reversal & 1.044 & 0.809 & - \\
\hline & Percentage of reversals & $47 \%$ & $39 \%$ & - \\
\hline
\end{tabular}

Source: own calculations 
Panel A includes measures drawn by comparing the daily logarithmic rate of a return on the day of expiration (or on the control day) to the daily logarithmic rate of return on the following day. The average Type 0 reversal for mWIG40 as well as for the individual stocks is positive on expiration days and negative on control days. This measure takes a positive value in the case of price reversal and negative otherwise, so the results are consistent with the assumption of reversal after the expiration and continuation in prices when no contract expires. However, the test statistic of the differences in means indicates that the difference between average Type 0 reversal on the expiration and control days is significant only in the group of individual stock prices. For the WIG20 index, the Type 0 reversal is positive both on expiration and control days, suggesting no reversal. The Type 1 and Type 2 reversals take strictly nonnegative values. These measures are only descriptive. The higher the value of the average measure, the stronger the phenomenon of price reversal. It can be noticed that the means of both measures are higher on expiration days than on control days only in the case of individual stocks; however, the differences are not substantial. In the table, the percentages of the number of days with reversals is presented (calculated as the percentage of the number of days with a positive Type 0 reversal). For the $\mathrm{mWIG} 40$ index as well as the individual stocks, this is higher on expiration days than on control days; but again, the differences are moderate.

The averaged measures presented in Panel B were calculated with the use of the daily logarithmic rate of return on the event day and the overnight return on the following day. The results are mostly consistent with those from Panel A. This time, however, the average Type $\mathrm{O}$ reversal has a positive sign on expiration days and negative on control days in each of the three groups (but the t-statistic values are not significant). Only for the individual stock returns, the difference between the average Type 0 reversal on expiration and control days can be detected at a 10\% level. The average Type 1 and Type 2 reversals for the stocks are somewhat higher in the group of expiration days. The values of these measures for WIG20 and mWIG40 do not confirm reversal after expiration.

From among the foregoing studies of price reversal after index future expiration that used such measures, Stoll and Whaley (1987) on the US market and Chamberlain et. al. (1989) on the Canadian market detect the phenomenon of price reversal, while Stoll and Whaley (1997) on the Australian market and Alkebäck and Hagelin (2004) on the Swedish market do not find it.

As in the analysis of the regression model, the measures do not indicate a reversal of the WIG20 and mWIG40 indexes, but they do suggest that such a reversal appears in the individual stock prices. 
Price reversal as potential expiration day effect of stock and index futures...

\subsection{Results from event study analysis of daily returns}

In this part of the research, a slightly different definition of price reversal is employed. As an event study analysis is normally based on the differences between actual returns and their expected values, price reversal here means that an unexpected rise in the returns on the following day occurs after an unexpected drop in returns on the day of expiration; conversely, returns that are higher than expected on the day of expiration are followed by returns lower than expected on the next day. This is not tantamount to literal meaning of the phrase "price reversal," which suggests that the price rose and then dropped (or vice versa).

To detect price reversal after future expiration using the event study methodology, each group of events (expiration of futures on WIG20, mWIG40, and for individual stocks) is divided into two subgroups: expiration days with positive abnormal returns and expiration days with negative abnormal returns. Then, an event study analysis is conducted in each of the two clusters with the use of a generalized rank test. The significance of the test statistic on the event day in the groups is obvious due to their definitions. The attention is focused on the day following expiration, so this day is treated as an event day. A test statistic significantly different from zero and with a sign opposite to the sign of a test statistic on expiration day is a signal of price reversal.

Table 3

Reaction of daily abnormal returns of individual stocks to expiration of futures

\begin{tabular}{|c|c|c|c|c|c|c|}
\hline \multirow{3}{*}{$t$} & \multicolumn{3}{|c|}{$\begin{array}{c}\text { Individual stocks } \\
\text { (positive abnormal returns } \\
\text { on day } t=0 \text { ) }\end{array}$} & \multicolumn{3}{|c|}{$\begin{array}{c}\text { Individual stocks } \\
\text { (negative abnormal returns } \\
\text { on day } t=0 \text { ) }\end{array}$} \\
\hline & $\overline{A R_{t}} \quad[\%]$ & $\tau$-grank & p-value & $\overline{A R_{t}} \quad[\%]$ & $\tau$-grank & p-value \\
\hline & \multicolumn{3}{|c|}{311 events } & \multicolumn{3}{|c|}{280 events } \\
\hline-5 & 0.055 & 1.040 & 0.304 & -0.075 & -0.253 & 0.802 \\
\hline-4 & 0.122 & 0.941 & 0.352 & 0.018 & 0.482 & 0.632 \\
\hline-3 & -0.007 & 0.618 & 0.540 & -0.033 & 0.464 & 0.645 \\
\hline-2 & 0.065 & 0.924 & 0.361 & 0.063 & 0.286 & 0.776 \\
\hline-1 & -0.055 & 0.285 & 0.777 & 0.049 & 0.843 & 0.404 \\
\hline 1 & -0.064 & -0.656 & 0.515 & 0.202 & 2.433 & 0.019 \\
\hline 2 & -0.188 & -1.224 & 0.228 & 0.104 & 2.337 & 0.024 \\
\hline 3 & -0.134 & -0.641 & 0.525 & -0.128 & -0.389 & 0.699 \\
\hline 4 & -0.123 & -0.121 & 0.904 & -0.024 & 1.001 & 0.322 \\
\hline 5 & -0.132 & -0.480 & 0.634 & 0.060 & 1.277 & 0.208 \\
\hline
\end{tabular}

Source: own calculations 
Table 3 presents the following results: the mean abnormal returns in percentages, value of the generalized rank test statistic, and p-values of the test for the research conducted on the individual stocks' daily logarithmic rate of returns. The event day is not included in the table, as the significance of the test statistic on this day is evident in view of the clusters' definitions. In the cluster of expiration days with positive abnormal stock returns, there is no value significantly different from zero throughout the event window. The mean abnormal returns and test statistic on days following an expiration day are negative; however, as they are not significant, they cannot support the assumption of price reversal after expiration. However, in the cluster of expiration days with negative abnormal returns, the test statistic on the two days following expiration are significantly positive (at a 5\% level). This means that the prices being lower than expected on the expiration day can be the effect of unwinding long arbitrage positions or speculations conducted on the stocks by investors who have tried to change the settlement price of the contract. After expiration, the prices return to the higher level. Long arbitrage (that is, buying stocks and selling a contract) is more popular than short arbitrage, as it is easier to conduct. Short arbitrage requires the short selling of stocks. Until the release of European Union regulations concerning short selling in May 2015, GPW had published lists of stocks that could have been the objects of short selling. The stocks were required to fulfill the appropriate requirements regarding liquidity. This had caused that short selling had not been practically used. The regulation from May 2015 made short selling easier to conduct, but most of the data in the research came from the period of time from before this change. If the unwinding of arbitrage positions poses an essential part of price changes on expiration day, it is not surprising that price reversal is visible only in the group of expiration days with negative returns, as simply unwinding long arbitrage is connected to selling stocks, resulting in price falls. Even if the speculations have an important influence on prices on expiration, price reversal should be stronger in the cluster of days with negative abnormal returns if arbitragers also have a contribution to this effect.

Analogous research was also conducted in the control group to check if the potential price reversal could be interpreted as the effect of expiration or if it might have been a calendar effect. Detailed results can be provided by the author upon request. All of the test statistic values in the event windows are insignificant, and in both clusters, the average abnormal return on the day following a control day have the same sign as the abnormal returns on day $t=0$, which rather suggests continuation than reversal in the returns. This supports the conclusion about reversal being caused by future expiration.

The results from the event study analysis conducted for the WIG20 and mWIG40 returns are presented in Table 4 . As in the case of the regression models and reversals measures, no evidence of reversal in the returns after expiration were found. 


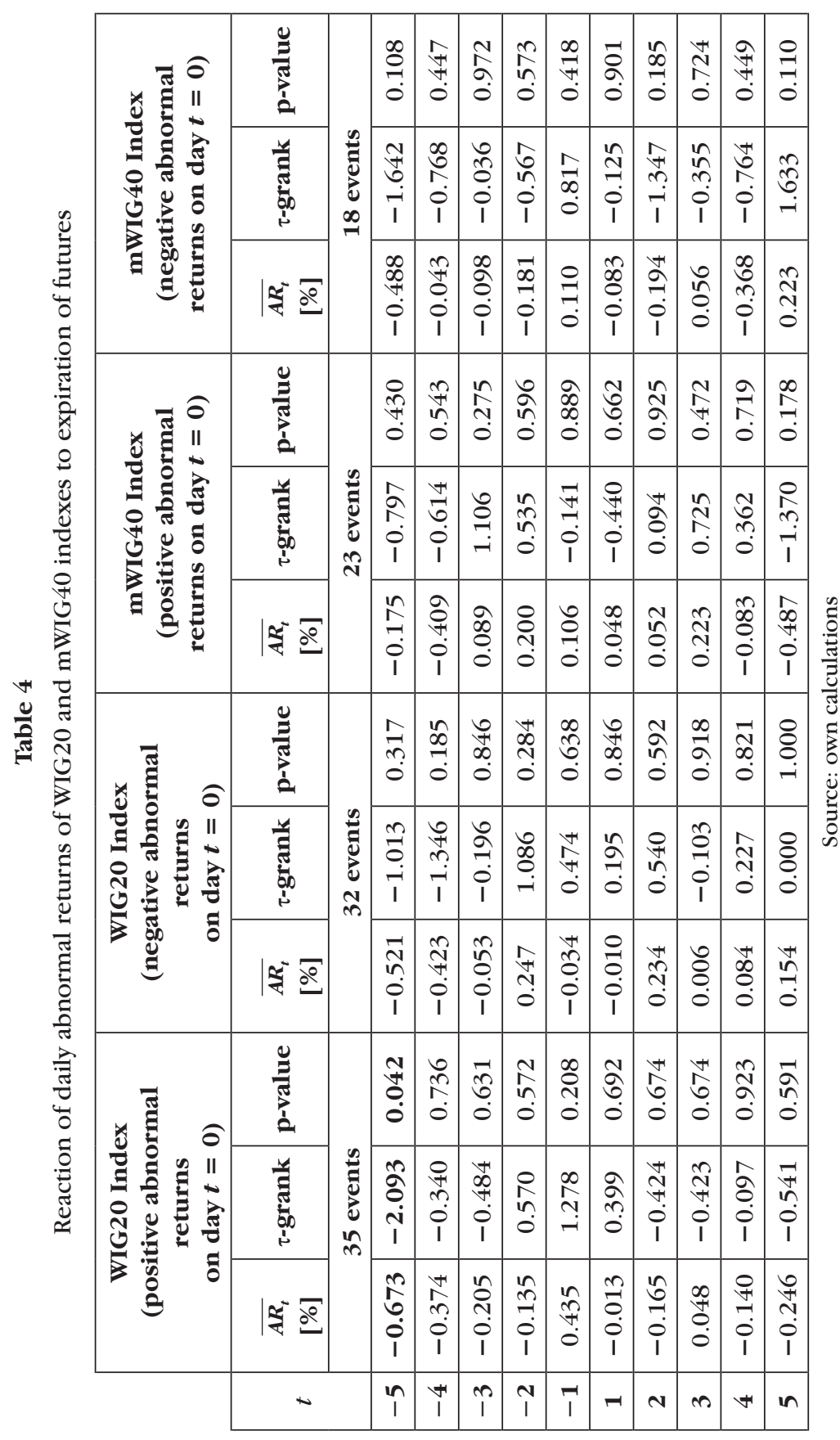


Most of the test statistic values in the event windows are not significantly different from zero. Only for WIG20 in the group of expiration days with positive returns, the value of the test statistic five days before expiration is significantly negative (at a 5\% level), but this seems to have no connection with the expiration. In the clusters constructed for WIG20 abnormal returns on control days (not presented in the article), there is no test statistic value significantly different from zero. In the case of the mWIG 40 Index, the only significant value (at a 5\% level) of the test statistic on control days appears in the cluster constructed for days with negative abnormal returns (three days before the control day, and it is also negative). However, the number of events in each sample constructed for mWIG40 is small. The distribution of the test statistic converges to t-student distribution as the sample size increases, so the results here are not quite reliable.

\subsection{Results from the event study analysis of overnight and daylong returns of individual stocks}

As the analysis of the individual stocks' daily returns gives the basis for the occurrence of the price reversal effect of future expiration, more-detailed research is conducted. Alkebäck and Hagelin (2004) suggested that day-to-day returns can be unable to reflect price reversal, as prices can reverse before the close of the market. To check whether the effect appears immediately after expiration and if it can be reflected in the overnight returns of the stocks, overnight abnormal returns are calculated with the use of the market model, and the generalized rank test is used analogously to the daily abnormal returns. Clusters of days with negative and positive abnormal returns are, however, defined in terms of daily abnormal returns on the expiration day, because the overnight returns on the expiration do not mirror the activity of investors on this day, so they are probably not influenced by the expiration. Results presented on the left-hand side of Table 5 show that, in both clusters of expiration days, the test statistic is significant (at a 1\% level) on the day after expiration, and the sign of the statistic is opposite to the sign of the abnormal returns on expiration. This is strong evidence that price reversal occurs immediately after expiration and is reflected in the overnight returns (even in the group of expiration days with negative returns, in which this effect was not reflected by the daily returns). Analogous research was conducted in the control group. These results can be provided by the author upon request. In the cluster of control days determined by positive abnormal daily returns, the test statistic is significant and positive on day $t=0$. This means that positive abnormal daily returns can be a continuation of some trend, as they occur after positive overnight returns. In the cluster of control days with negative abnormal returns, the test statistic is significantly positive (at a 5\% level) two days after the event day, but it is difficult for the author to find a potential reason for this significance. 
In the next part of the research of the individual stocks returns, the same study is conducted on daylong abnormal returns. Daylong returns are calculated as the natural logarithm of the ratio of stock prices at the close and at the opening on a given day. Abnormal daylong returns are calculated with the use of the market model. The event study was conducted in two clusters, which are defined (as previously) in terms of the sign of the daily abnormal returns on the expiration day. These results are presented on the right-hand side of Table 5. The test statistics are significant on day $t=0$ in both clusters, which is not surprising (as the daylong returns are usually the same sign as the corresponding daily returns). This time, in the two clusters for expiration days, there is no significance of the test statistic on day $t=1$. This suggests that, even on days with negative daily returns (in which the research conducted on the daily returns gives a significant and positive statistic on the day following the expiration day), the phenomenon of price reversal occurs immediately after expiration. However, it is stronger in this case and can have a continuation, as the test statistic is also significant (at a 5\% level) on the second day after expiration. In the two clusters for the control days (not presented), the abnormal daylong returns follow this trend. The test statistic is significant and positive one day after day $t=0$ with the positive abnormal returns. In the second cluster, the statistic is not significantly different from zero on each of the days after day $t=0$, but it is negative through the end of the event window.

As a complement to the research, the event study analysis was also conducted with the use of normal daily returns. The methodology is the same as previously; but now, the expected value of the return is assumed to be equal to zero. Thereby, abnormal returns are equal to the normal daily returns. The significant test statistic on day $t=1$ with the sign opposite to the sign of the test statistic on the event day suggests a price reversal. Here, the reversal is consistent with the definition employed in the regression models and reversal measures. The results are not presented to avoid making the article too weighty, but they can be provided by the author upon request. They are similar to those from the analysis of daily abnormal returns. In the case of the individual stocks, there is no clear-cut evidence of the reversal in the cluster with positive returns upon expiration. In the cluster with negative returns on day $t=1$, the test statistic is significantly positive (at a 5\% level) on the day following expiration. This supports the previous results that, in this cluster, the reversal is more visible. In the case of WIG20 and $\mathrm{mWIG} 40$ returns, no test statistic values statistically different from zero could be found throughout the entire event window. Like the previous methods, this one also does not detect a reversal in the indexes' returns after future expiration. 


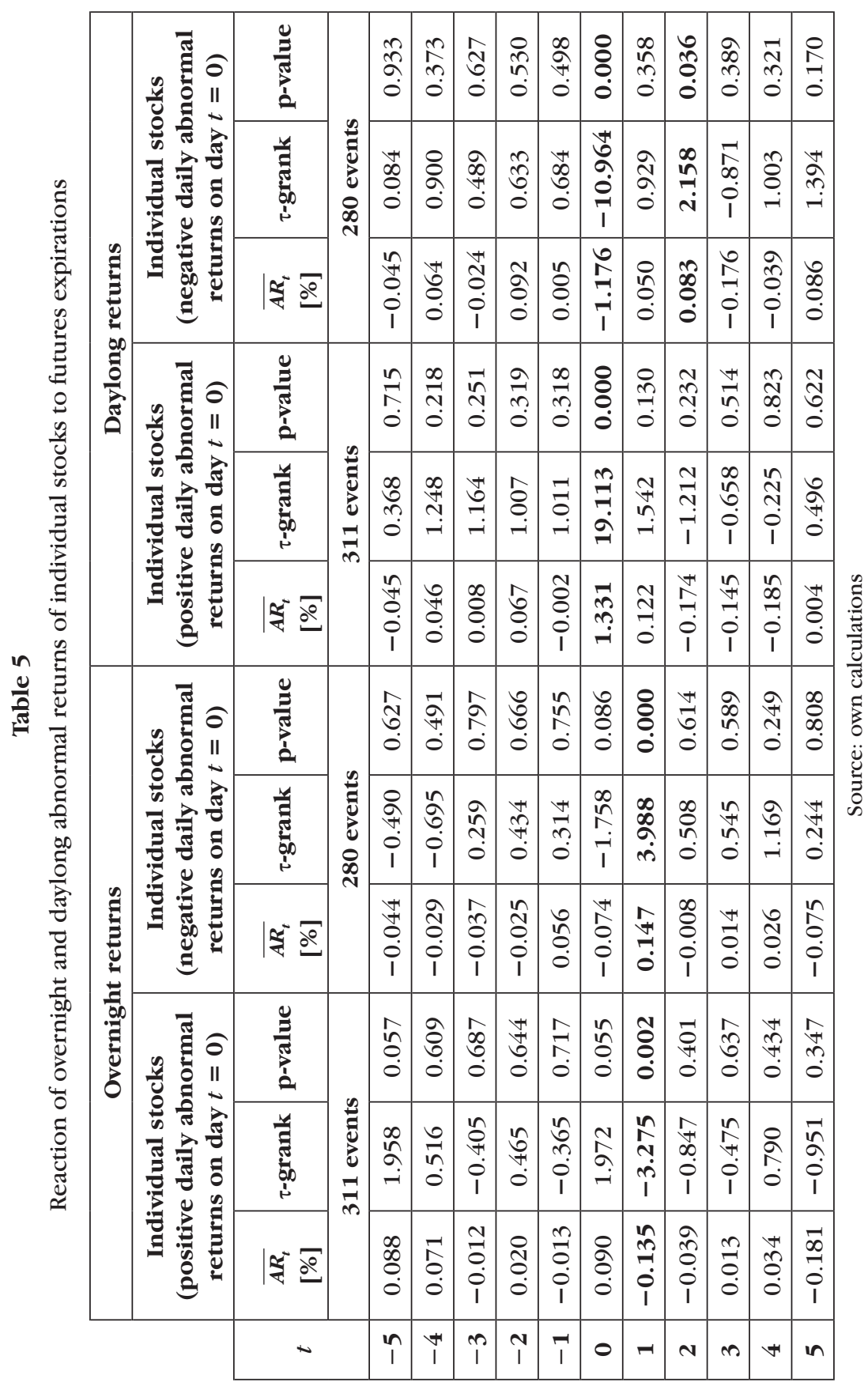




\section{Conclusions}

In this paper, the impact of futures' expiration days on the returns of their underlying assets was researched. The data covers the period from January 2001 to December 2016. Three potential effects of future expiration are evident in the literature: increased trading volume on the day of expiration, increased volatility in the prices, and abnormal price changes upon expiration resulting in price reversal on the following day. The author focused on the last of the above-mentioned effects and conducted detailed research on abnormal price changes around the expiration of futures on the WI20 and mWIG40 indexes as well as futures on individual stocks. Three different methods were employed to investigate the occurrence of the phenomenon of price reversal. First, linear regression models were constructed with returns on the day following expiration as a dependent variable as well as returns on the day of expiration as an explanatory variable. Then, three measures of price reversal given by other researchers were calculated. Finally, an event study analysis was employed to test the occurrence of price reversal (which is defined in a slightly different way than in the two previous methods).

The research does not detect the reversal of index returns and, thus, does not confirm the previous results on this issue obtained by Morawska (2007). In the case of the individual stock returns, all three methods support the assumption that price reversal occurs after expiration. Results from the regression model as well as from the event study analysis show that the reversal is immediate and is reflected in overnight returns more than in daily returns. The phenomenon of price reversal seems to be stronger in the case of negative abnormal returns on the expiration day. Author suggests that it can be connected with the unwinding of long arbitrage positions. Short arbitrage, which involves the short selling of stocks, was constricted during the period under study due to the restrictive regulations regarding short selling.

The differences in the results obtained for the stocks and the indices are not surprising. The way the contracts are settled is a very important factor that influences the effects of expiration day. The final settlement price of futures on individual stocks is calculated as the rate of the stock from the last transaction on the expiration day. Thus, to manipulate the settlement price, speculators should increase their activity mostly at the close of the market. Long arbitragers (with long positions in stocks) have only to place market-on-close orders on the stocks to realize their strategies. In the case of index futures, the final settlement rate is equal to the mean of the continuous quotations from the last trading hour and the value at the close, where the five highest and five lowest values are eliminated. Speculation on an index is more difficult than on individual stocks, as an investor has to buy or sell only this one stock to manipulate the price of the stock. To manipulate the index, it is necessary to make appropriate transactions on all of the stocks in it. Changing the value of the index is quite difficult as the indices represent the entire 
market; therefore, as Stoll and Whaley (1986) write, they "are deeper and broader than the market in any stock." Construction of the settlement rate of index futures additionally restricts speculation on it in order to manipulate a contract's price.

The index arbitrage is also intrinsically more complex than the arbitrage on a single stock and is further hampered by the settlement procedure of index futures. Focusing on a long arbitrage (which is more-readily-available on the Polish market), the settlement procedure makes that unwinding a position in the stocks by ordinary market-on-close orders does not give an investor profits exactly equal to the costs associated with the trade of the contract.

All of the above-mentioned reasons suggest that the price effects of future expiration are more likely in stock prices than in the returns of the indices, and the results of the research confirm this thesis. There can be one additional reason why price effects in indice returns were not found. This research uses daily data. Alkebäck and Hagelin (2004) wrote that it is an "important methodological concern, whether lower frequency data allow expiration day effects to be detected." They give two arguments supporting the thesis that daily returns can be unable to detect price effects. First, extending the event window reduces the relative size of the effect, thereby reducing the probability of detection. Moreover, prices can be reversed before the exchange close, and the day-to-day returns cannot reflect the price distortion. The results from the analysis of the daily and overnight returns of the stocks reinforce the second argument. However, in the case of the WIG20 and $\mathrm{mWIG} 40$ indexes, an event study on the overnight returns was also conducted by the author; however, as it does not show any significant test statistic value in the event window, the results are not included in the article. Nevertheless, the issue of whether higher-frequency data is better able to detect expiration effects remains an open question that inspires this author to further study their use.

\section{References}

[1] Alkebäck, P. and Hagelin, N. (2004) 'Expiration Day Effects of Index Futures and Options: Evidence from a Market with a Long Settlement Period,' $A p$ plied Financial Economics, vol. 14, issue 6, pp. 385-396.

[2] Bollen, N.P.B. and Whaley, R.E. (1999) 'Do expiration of Hang Seng Index derivatives affect stock market volatility?', Pacific-Basin Finance Journal, vol. 7, pp. 453-470.

[3] Chamberlain, T.W., Cheung, S.C. and Kwan, C.C.Y. (1989) 'Expiration-day effects of index futures and options: Some Canadian evidence,' Financial Analysts Journal, vol. 45, No. 5, pp. 67-71.

[4] Chen, C. and Williams, J. (1994) 'Triple-witching hour, the change in expiration timing, and stock market reaction,' Journal of Futures Markets, vol. 14, pp. 275-292. 
[5] Chow, Y.F., Yung, H.H.M. and Zhang, H. (2003) 'Expiration day effects: The case of Hong Kong,' Journal of Futures Markets, vol. 23, pp. 67-86.

[6] Day, T.E. and Lewis, C.M. (1988) 'The behaviour of the volatility implicit in the prices of stock index options,' Journal of Financial Economics, vol. 22, pp. 103-122.

[7] Diz, F. and Finucane, T.J. (1998) 'Index option expirations and market volatility,' Journal of Financial Engineering, vol. 7, pp. 1-23.

[8] Fung, J.K.W. and Jung, H.H.M. (2009) 'Expiration-Day Effects - An Asian Twist,' Journal of Futures Markets, vol. 29, pp. 430-450.

[9] Gurgul, H. (2006) Analiza zdarzeń na rynkach akcji, Kraków: Oficyna Ekonomiczna.

[10] Illueca, M. and Lafuente, J.Á. (2006) 'New evidence on expiration-day effects using realized volatility: An intraday analysis for the Spanish stock exchange,' Journal of Futures Markets, vol. 26, pp. 923-938.

[11] Lien, D. and Yang, L. (2005) 'Availability and settlement of individual stock futures and options expiration-day effects: evidence from high-frequency data,' The Quarterly Review of Economics and Finance, vol. 45, pp. 730-747.

[12] Karolyi, G.A. (1996) 'Stock market volatility around expiration days in Japan,' Journal of Derivatives, vol. 4, No. 2, pp. 23-43.

[13] Kolari, J. and Pynnönen, S. (2001) 'Nonparametric rank tests for event studies,' Journal of Empirical Finance, vol. 18, pp. 953-971.

[14] Morawska, H. (2004) 'Wpływ efektu trzech wiedźm na okresowe kształtowanie się cen instrumentu bazowego,' Zeszyty Naukowe Uniwersytetu Szczecińskiego. Finanse. Rynki finansowe. Ubezpieczenia, No. 2, vol. 2, pp. 403-416.

[15] Morawska, H. (2007) 'Wpływ dnia wygaśnięcia indeksowych kontraktów terminowych i opcji na rynek kasowy GPW w Warszawie SA,' in Gabryelczyk, K., Ziarko-Siwek, U. (eds.) Inwestycje finansowe, Warszawa: CeDeWu.

[16] Narang, S. and Vij, M. (2013) 'Long-Term Effects of Expiration of Derivatives on Indian Spot Volatility,' ISRN Economics, vol. 2013, pp. 1-6.

[17] Schlag, C. (1996) 'Expiration day effects of stock index derivatives in Germany,' European Financial Management, No. 1, vol. 2, pp. 69-95.

[18] Stoll, H.R. and Whaley, R.E. (1986) 'Expiration Day Effects of Index Options and Futures,' Monograph Series in Finance and Economics, Monograph 1986-3.

[19] Stoll, H.R. and Whaley, R.E. (1987) 'Program Trading and Expiration-Day Effects,' Financial Analysts Journal, vol. 43, No. 2, pp. 16-28.

[20] Stoll, H.R. and Whaley, R.E. (1990) 'Program trading and individual stock returns: Ingredients of the triple-witching brew,'Journal of Business, vol. 63, pp. 165-192.

[21] Stoll, H.R. and Whaley, R.E. (1997) 'Expiration-day effects of the all ordinaries share price index futures: Empirical evidence and alternative settlement procedures,' Australian Journal of Management, vol. 22, No. 22, pp. 139-174. 


\section{Appendix}

Table 6 contains list of futures used in the research with their characteristics. The names of the underlying assets are given by their abbreviations. The first expiration means the first one included in the research. If the contract was introduced before the period under study, it is not its first expiration at all.

Table 6

A list of futures used in research and their characteristics

\begin{tabular}{|c|c|c|c|}
\hline $\begin{array}{l}\text { Underlying asset } \\
\text { (abbreviation) }\end{array}$ & Multiplier & First expiration & $\begin{array}{c}\text { Number of } \\
\text { expiration days } \\
\text { (with positive number } \\
\text { of opened positions) }\end{array}$ \\
\hline WIG20 & $10,20 *$ & 13-06-2001 & 64 \\
\hline mWIG40 & 10 & $15-06-2007$ & 39 \\
\hline ACP & 100 & $18-06-2010$ & 27 \\
\hline ALR & 100 & 21-03-2014 & 9 \\
\hline ATT & 100 & $16-12-2016$ & 1 \\
\hline BRS & 1,000 & $15-06-2012$ & 13 \\
\hline BZW & 100 & $20-06-2003 * *$ & 24 \\
\hline CCC & 100 & $18-12-2015$ & 4 \\
\hline CDR & 100 & $16-09-2011$ & 22 \\
\hline CIE & 100 & $16-12-2016$ & 1 \\
\hline CPS & 100 & $18-12-2015$ & 4 \\
\hline ENA & 100 & $18-12-2015$ & 5 \\
\hline GPW & 100 & 16-03-2012 & 20 \\
\hline GTC & 1,000 & $16-12-2011$ & 14 \\
\hline ING & 100 & $16-12-2016$ & 1 \\
\hline JSW & 100 & $16-12-2011$ & 21 \\
\hline KER & 100 & $16-12-2011$ & 15 \\
\hline KGH & 100 & 21-03-2003 & 56 \\
\hline KRU & 100 & $16-12-2016$ & 1 \\
\hline LTS & 100 & 26-06-2011 & 23 \\
\hline LWB & 100 & $16-12-2011$ & 21 \\
\hline
\end{tabular}


Price reversal as potential expiration day effect of stock and index futures...

Table 6 cont.

\begin{tabular}{|c|c|c|c|}
\hline MBK & 100 & $16-12-2016$ & 1 \\
\hline MIL & 1,000 & $20-06-2003 * * *$ & 17 \\
\hline OPL & 100 & $21-03-2014$ & 12 \\
\hline PEO & 100 & $21-03-2003$ & 56 \\
\hline PGE & 100 & $18-06-2010$ & 27 \\
\hline PGN & 1,000 & $18-06-2010$ & 27 \\
\hline PKN & 100 & $21-03-2003$ & 56 \\
\hline PKO & 100 & $16-09-2005$ & 46 \\
\hline PZU & 100 & $17-09-2010$ & 26 \\
\hline SNS & 1,000 & $21-09-2012$ & 17 \\
\hline TPE & 1,000 & $18-03-2011$ & 24 \\
\hline
\end{tabular}

* First futures on WIG20 Index with multiplier 20 were put on the market in September 2013.

** Contracts on BZW had been traded through December 2008. Then, the markings were suspended and restarted in December 2016.

*** Contracts on MIL had been traded through March 2007. Then, the markings were suspended and restarted in December 2015.

Source: own compilation on the basis of data from www.gpwinfostrefa.pl 